\title{
Surgery with emicizumab prophylaxis for two pediatric patients with severe haemophilia A with inhibitors
}

Marguerite Lockhart ${ }^{1}$, Brigitte TARDY-PONCET ${ }^{2}$, Aurélie Montmartin ${ }^{3}$, Pauline Noyel ${ }^{1}$, Sandrine Thouvenin-Doulet ${ }^{4}$, and Claire Berger ${ }^{1}$

${ }^{1}$ CHU Saint-Étienne

${ }^{2}$ EA 3065, Université Jean-Monnet, INSERM CIC 1408

${ }^{3}$ U1059 INSERM

${ }^{4}$ University Hospital, Saint Etienne

November 12, 2020

\begin{abstract}
Emicizumab is a prophylaxis for patients with severe haemophilia A with inhibitor. Despite the daily prophylaxis, coagulation states stay below normal value and cannot be assessed by standard hemostasis techniques. In our two patients, we use thrombin generation assay (endogenous thrombin potential (ETP) and Peak) to monitor the patient's clotting status. Under emicizumab,

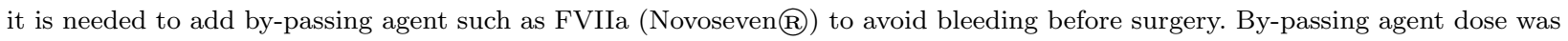
chosen with the help of thrombin generation assay and after collegial concertation.
\end{abstract}

TITLE PAGE

Surgery with emicizumab prophylaxis for two pediatric patients with severe haemophilia A with inhibitors

Marguerite LOCKHART*, Brigitte TARDY-PONCET ${ }^{+}$, Aurélie MONTMARTIN ${ }^{++}$, Pauline NOYEL ${ }^{\text {SS }}$, Sandrine THOUVENIN*, Claire BERGER*, P

*Hematology and Oncology Pediatric Unit, Haemophilia CRC Hospital of Saint Etienne,

+ INSERM CIC 1408 Laboratory of Hematology;

${ }^{++}$Inserm U1059, Sainbiose Dysfonction Vasculaire et Hemostase, Universite de Lyon, Saint-Etienne, France;

${ }^{\mathrm{SS}}$ Biology LaboratoryUniversityHospital of Saint Etienne;

${ }^{\mathrm{P}}$ EA SNA-EPIS 4607, Universite Jean Monnet, Saint Etienne

LOCKHART Marguerite, Hematology and Oncology Pediatric Unit, Haemophilia CRC Hospital of Saint Etienne, avenue Albert Raimond, 42270 Saint priest en Jarez, FRANCE

Tel :+33(0)684228278 e-mail :margueritebouron@gmail.com

Word count for

1. Abstract : 85 words

2. Main Text 1199

3. Number of Tables : 2 
4. A short running title: thrombin generation assay with emicizumab and BPA

5. Key words: Severe haemophilia, surgery, emicizumab, pediatric, thrombin generation assay, by passing agent prophylaxis

6. Abbreviations key

\begin{tabular}{ll}
\hline BPA & By-passing agent \\
\hline TGA & Thrombin generation assay \\
ITI & Immune tolerance induction \\
aPCC & Activated prothrombin complex concentrate \\
ABR & Annual Bleeding Rate \\
ETP & Endogenous thrombin potential \\
PRP & Platelet-rich plasma \\
TG & Thrombin generation \\
\hline
\end{tabular}

\begin{abstract}
S
Emicizumab is a prophylaxis for patients with severe haemophilia A with inhibitor. Despite the daily prophylaxis, coagulation states stay below normal value and cannot be assessed by standard hemostasis techniques. In our two patients, we use thrombin generation assay (endogenous thrombin potential (ETP) and Peak) to monitor the patient's clotting status. Under emicizumab, it is needed to add by-passing agent such as FVIIa (Novoseven ( $)$ ) to avoid bleeding before surgery. By-passing agent dose was chosen with the help of thrombin generation assay and after collegial concertation.
\end{abstract}

\title{
MAIN TEXT
}

\section{Introduction}

Severe haemophilia A is a X-linked bleeding disorder due to factor VIII deficiency[1]. It decreases thrombin generation (TG) potential[2]. Inhibitor[3], [4] complicated replacement treatment (factor VIII concentrates[5]). Emicizumab (bispecific humanized monoclonal antibody) is an effective treatment for severe haemophilia A with inhibitor[6], [7]. It bridges activated factor IX and X to restore missing activated factor VIII[8]. Patients under emicizumab (Hemlibra@ $\mathbb{B}$, Roche, Bazel, Switzerland) bleed less than patients under bypassing agent (BPA)[9],[10]. They still have acute bleeding needed BPA, mainly FVIIa (Novoseven@ ,rVIIa, Novonordisk, Bagsvaerd, Denmark)[11]. Surgeries require BPA for bleeding risk but BPA doses for patients under emicizumab are not defined. Thrombin generation assay (TGA)[12] has been used to monitor surgery with Novoseven \& [13] and could assess haemostasis when emicizumab and BPA are combined[14].

\section{Results}

\section{Case n.1}

A 14 year old boy with severe haemophilia A developed inhibitor after 14 exposure days to an antigen (rFVIII, ADVATE@ Baxter Healthcare, Zurich, Switzerland)[15]. He received Immune tolerance induction (ITI) with FVIIIs (ADVATE@), pdF VIII FACTANE@,Laboratoire Français du Fractionnement des Biotechnologies (LFB), Les Ulis, France; OCTANATE@, Octapharma AG, Lachen, Switzerland). Last inhibitor titer was $22.8 \mathrm{UB} / \mathrm{mL}$. He received BPA (FVIIa and activated prothrombin complex concentrate (aPCC)) for bleeding and prophylaxis, his Annual Bleeding Rate (ABR) stay at 12. Emicizumab was started at 13 years old : initiation phase with $3 \mathrm{mg} / \mathrm{kg} /$ week the first 4 weeks followed by stabilisation phase with $1.5 \mathrm{mg} / \mathrm{kg} / \mathrm{week}[9]$. During initiation phase, TG (endogenous thrombin potential (ETP) and Peak) was measured just before emicizumab injection (Table 1). Before the $4^{\text {th }} 3 \mathrm{mg} / \mathrm{kg}$ dose, residual ETP was $1041 \mathrm{nM}^{*}$ min and Peak was 50.1 nM. 4 weeks after stabilisation phase, ETP and Peak (6 days after injection) were lower than previously (895 $\mathrm{nM}^{*}$ min and $39.7 \mathrm{nM}$ ) (Table 2) and lower than normal defined in 40 healthy volunteers. We decided to add Novoseven ( ) for surgery. To assess which dose of FVIIa would provide safe bleeding 


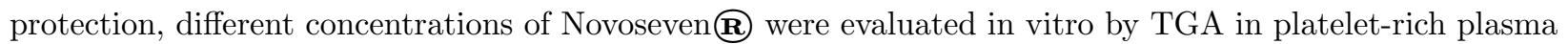
(PRP)[13]. We spiked patient PRP collected 6 days after $1.5 \mathrm{mg} / \mathrm{kg}$ emicizumab injection with different Novoseven@Concentrations (Table 2). In vitro, with $45 \mu \mathrm{g} / \mathrm{kg}$ of Novoseven@ $\mathbb{B}$, ETP was normalized (1159 $\mathrm{nM}^{*}$ min) ; with $90 \mu \mathrm{g} / \mathrm{kg}$ ETP was normalized (1219 $\left.\mathrm{nM}^{*} \min \right)$ and we had a better response for Peak (54.5 $\mathrm{nM})$. We chose $45 \mu \mathrm{g} / \mathrm{kg}$ for surgery as ETP was in normal range.

After 10 weeks of emicizumab, central catheter (Broviak type) was removed. We perfused $45 \mu \mathrm{g} / \mathrm{kg}$ of Novoseven ( 30 minutes before surgery. On surgery day, TG at basal was performed 5 days after $1.5 \mathrm{mg} / \mathrm{kg}$ emicizumab injection (ETP $796.48 \mathrm{nM}^{*}$ min, Peak $36.12 \mathrm{nM}$ ) and were lower than previously. TG measured ex vivo after rVIIa infusion the day of surgery was lower than in vitro after rVIIa spiking (Table 2). Surgery went safely.

\section{Case n.2}

A 15 year old boy with severe haemophilia A developed inhibitor after 9 exposure days to B-domain-deleted rFVIII (Refacto@, moroctocog alpha, Wyeth, Cambridge, MA, USA)[15]. He received ITI with FVIIIs (Refacto@), Kogenate@ (Bayer AG, Leverkusen, Germany),Factane@), Octanate@ ). Last inhibitor titer was 30.4 UB/Ml. He received BPA (Novoseven@ and then FEIBA@) for haemarthrosis, ABR stay at 6 . He started emicizumab at 14 years old. During the $1^{\text {st }} 4$ weeks, ETP and Peak were measured before injection (Table 1). At the end of initiation phase, residual ETP was $844 \mathrm{nM}^{*}$ min and Peak was $35.6 \mathrm{nM}$. 4 weeks after stabilisation phase, ETP and Peak (3 days after injection) were higher than previously (949 $\mathrm{nM}^{*}$ min and $\left.49.1 \mathrm{nM}\right)$. TG stayed below normal, we added Novoseven@ $\mathbb{B}$ for surgery. We spiked patient PRP collected 3 days after $1.5 \mathrm{mg} / \mathrm{kg}$ emicizumab injection. With $90 \mu \mathrm{g} / \mathrm{kg}$ of Novoseven@ , we observed no effect in vitro on ETP $\left(939 \mathrm{nM}^{*}\right.$ min) and slight effect on Peak $(54,5 \mathrm{nM})$; with $120 \mu \mathrm{g} / \mathrm{kg}$, ETP $(1069$ Nm*min) and Peak (69nM) were normalized. $90 \mu \mathrm{g} / \mathrm{kg}$ (usual recommended dose) was chosen for surgery[16]. Central catheter was removed after ten weeks of emicizumab treatment and 30 minutes after $90 \mu \mathrm{g} / \mathrm{kg}$ of Novoseven ( ) . Basal TG values on surgery day measured 2 days after $1.5 \mathrm{mg} / \mathrm{kg}$ emicizumab injection (ETP $1012 \mathrm{nM}^{*}$ min, Peak 63.12nM) were higher than TG measured on spiking day. TG measured ex vivo after rVIIa infusion was higher than TG measured in vitro after rVIIa spiking (Table 2).

\section{Discussion}

TGA on patient's PRP[17] can evaluate patient coagulation status at different times of emicizumab treatment. TGA was performed every week, during treatment initiation phase, prior to administration of emicizumab weekly loading doses, ETP and Peak increased over time during the first month. ETP and Peak vary at basal, in our two cases it appears that there is a slight variability of TG at baseline from 6 to $25 \%$. Correction with emicizumab seemed to depend on basal level of TG for each patient. During stabilisation phase, ETP and Peak levels seemed to vary depending on delay between emicizumab injection and sample collection, suggesting that ETP and Peak levels during stabilisation phase are not constant. TG induced by emicizumab might be correlated with its pharmacokinetics (bioavailability after absorption, distribution and elimination). It has been described that emicizumab mean absorption half-life is $1.6+/-1$ day and elimination half-life is 28 days[18], suggested that increase of TG might be fast after emicizumab injection and decrease over a week. It could be interesting to correlate blood levels of emicizumab[19] and TG, as an additional factor to explain TG variability.

TG under emicizumab stay below normal. BPA was added for surgery[20]. In vitro spiking was only performed with Novosevenß [21]. For case $n^{\circ} 1$, according to our spiking results, $120 \mu \mathrm{g} / \mathrm{kg}$ of Novosevenß $\mathbb{B}$ should have been used the day of surgery (ETP and Peak were closer to normal). TG capacity on the day of surgery was $79 \%$ of normal without BPA and $90 \%$ after BPA. Minimum level of TG to achieve an effective haemostasis is unknown. Another case report suggests that low TG capacity at $69 \%$ of normal on surgery'day and low TG capacity at $25 \%$ of normal few days after surgery might be sufficient for efficient haemostasis[22]. Low doses of BPA were sufficient here for safe surgery[23].

For case $n^{\circ} 2$, on surgery'day TG capacity was $100 \%$ of normal without BPA and $108 \%$ after BPA. It suggested that BPA dose should be selected and adjusted according to basal TG values at T0 when BPA is necessary. 
BPA doses were lower compared to other studies[21],[24].

Use of BPA for patients under emicizumab depend on surgery type. In HAVEN 1-4 studies, 214 minor surgeries were performed, minor surgeries were mostly dental $(\mathrm{n}=63)$ and central venous access device procedures $(\mathrm{n}=34)$. All patients with haemophilia A with inhibitors had rFVIIa prophylaxy for surgeries[25].

In conclusion, TGA in patients with severe haemophilia A under emicizumab could evaluate patient coagulation state, even if TG is not perfectly stable over time. Interferences between emicizumab and rFVIIa are not all known and TG interpretation is difficult when performed together. Ex vivo TG results on patients

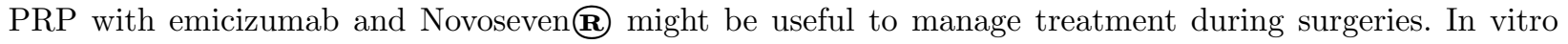
spiking might be performed with the same delay after emicizumab than the day of surgery to better reflect the in vivo.

For future, we could dose emicizumab in blood to interpret TG. It could be interesting to determine minimal ETP and Peak necessary for safe surgery.

\section{Acknowledgements}

C.B., S.T., M.L. are clinicians who took care of the two patients; B.T. performed thrombingeneration test; A.M and P.N.arebiologists, who looked for inhibitors and performed thrombin generation test

Conflict of Interest statementThe authors stated that they had no interest which might be perceived as posing a conflict or bias.

\section{REFERENCES}

1. Mannucci PM, Tuddenham EGD. The Hemophilias - From Royal Genes to Gene Therapy. N Engl J Med , 2001 344: 1773-1779.

2. Baglin T. The measurement and application of thrombin generation. Br J Haematol , 2005 130: 653-661.

3. Inhibitors in congenital coagulation disorders - Key - 2004 - British Journal of Haematology

4. Owaidah T, Momen AA, Alzahrani H, Almusa A, Alkasim F, Tarawah A, Nouno RA, Batniji FA, Alothman F, Alomari A, Abu-Herbish S, Abu-Riash M, Siddiqui K, Ahmed M, Mohamed S, Saleh M. The prevalence of factor VIII and IX inhibitors among Saudi patients with hemophilia. Medicine (Baltimore), 201796

5. Aledort L, Ljung R, Mann K, Pipe S. Factor VIII therapy for hemophilia A: current and future issues. Expert Rev Hematol , 2014 7: 373-385

6. Scott LJ, Kim ES. Emicizumab-kxwh: First Global Approval. Drugs , 2018 78: 269-274.

7. Oldenburg J, Mahlangu JN, Kim B, Schmitt C, Callaghan MU, Young G, Santagostino E, Kruse-Jarres R, Negrier C, Kessler C, Valente N, Asikanius E, Levy GG, Windyga J, Shima M. Emicizumab Prophylaxis in Hemophilia A with Inhibitors. N Engl J Med , 2017 377: 809-818.

8. Nogami K. Bispecific antibody mimicking factor VIII. Thromb Res, 2016 141: S34-S35.

9. Mahlangu J, Oldenburg J, Paz-Priel I, Negrier C, Niggli M, Mancuso ME, Schmitt C, Jiménez-Yuste V, Kempton C, Dhalluin C, Callaghan MU, Bujan W, Shima M, Adamkewicz JI, Asikanius E, Levy GG, Kruse-Jarres R. Emicizumab Prophylaxis in Patients Who Have Hemophilia A with Inhibitors. N Engl J Med , 2018 379: 811-822

10. Le Quellec S. Clinical Evidence and Safety Profile of Emicizumab for the Management of Children with Hemophilia A. Drug Des Devel Ther, 2020 14: 469-481.

11. Young G, Sidonio RF, Liesner R, Oldenburg J, Chang T, Uguen M, Dhalluin C, Schmitt C, Levy GG, Shima M, Mahlangu J. HAVEN 2 Updated Analysis: Multicenter, Open-Label, Phase 3 Study to Evaluate Efficacy, Safety and Pharmacokinetics of Subcutaneous Administration of Emicizumab Prophylaxis in Pediatric Patients with Hemophilia A with Inhibitors. Blood , 2017 130: 85-85. 
12. Dargaud Y, Lambert T, Trossaert M. New advances in the therapeutic and laboratory management of patients with haemophilia and inhibitors. Haemophilia , 2008 14: 20-27

13. Dargaud Y, Lienhart A, Negrier C. Prospective assessment of thrombin generation test for dose monitoring of bypassing therapy in hemophilia patients with inhibitors undergoing elective surgery. Blood , 2010 116: $5734-5737$.

14. Dargaud Y, Lienhart A, Janbain M, Le Quellec S, Enjolras N, Negrier C. Use of thrombin generation assay to personalize treatment of breakthrough bleeds in a patient with hemophilia and inhibitors receiving prophylaxis with emicizumab. Haematologica , 2018 103: e181-e183

15. Mathieu S, Crampe C, Dargaud Y, Lavigne-Lissalde G, Escuriola-Ettingshausen C, Tardy B, Meley R, Thouvenin S, Stephan JL, Berger C. Challenges of the management of severe hemophilia A with inhibitors: two case reports emphasizing the potential interest of a high-purity human Factor VIII/von Willebrand factor concentrate and individually tailored prophylaxis guided by thrombin-generation test. Blood Coagul Fibrinolysis, 2015 26: 940-945.

16. Coppola A. Treatment of hemophilia: a review of current advances and ongoing issues. J Blood Med, 2010183.

17. Hoffman M, Dargaud Y. Mechanisms and monitoring of bypassing agent therapy. J Thromb Haemost JTH , 2012 10: 1478-1485.

18. New drug: Emicizumab for haemophilia A. Aust Prescr , 2019 42: 29

19. Shima M, Nogami K, Nagami S, Yoshida S, Yoneyama K, Ishiguro A, Suzuki T, Taki M. A multicentre, open-label study of emicizumab given every 2 or 4 weeks in children with severe haemophilia A without inhibitors. Haemoph Off J World Fed Hemoph , 2019 25: 979-987.

20. Oldenburg J, Mahlangu JN, Bujan W, Trask P, Callaghan MU, Young G, Asikanius E, Peyvandi F, Santagostino E, Kruse-Jarres R, Negrier C, Kessler C, Xu J, Windyga J, Shima M, von Mackensen S. The effect of emicizumab prophylaxis on health-related outcomes in persons with haemophilia A with inhibitors: HAVEN 1 Study. Haemoph Off J World Fed Hemoph , 2018.

21. Kruse-Jarres R, Callaghan MU, Croteau SE, Jimenez-Yuste V, Khoo L, Liesner R, Matsushita T, Recht M, Young G, Chang T, Dhalluin C, Mu Y, Xu J, Devenport J, Ko RH, Solari P, Oldenburg J. Surgical Experience in Two Multicenter, Open-Label Phase 3 Studies of Emicizumab in Persons with Hemophilia A with Inhibitors (HAVEN 1 and HAVEN 2). Blood , 2017 130: 89-89.

22. Dargaud Y, Lienhart A, Meunier S, Hequet O, Chavanne H, Chamouard V, Marin S, Negrier C. Major surgery in a severe haemophilia A patient with high titre inhibitor: use of the thrombin generation test in the therapeutic decision. Haemophilia , 2005 11: 552-558

23. Srivastava, Chandy, Sunderaj, Lee, Daniel, Dennison, Nair, Mathews, Anderson, Nair, Moses, Sudarsanam. Low-dose intermittent factor replacement for post-operative haemostasis in haemophilia. Haemophilia , 1998 4: 799-801

24. Kizilocak H, Yukhtman CL, Marquez-Casas E, Lee J, Donkin J, Young G. Management of perioperative hemostasis in a severe hemophilia A patient with inhibitors on emicizumab using global hemostasis assays. Ther Adv Hematol , 201910.

25. Santagostino E, Oldenburg J, Chang T, Xu J, Chebon S, Doral M. Surgical Experience from Four phase III Studies (Haven 1-4) of Emicizumab in Persons with Haemophilia A (PwHA) with or without FVIII inhibitors, 2019.

\section{Hosted file}

table 1.pdf available at https://authorea.com/users/375120/articles/492481-surgery-withemicizumab-prophylaxis-for-two-pediatric-patients-with-severe-haemophilia-a-with- 


\section{inhibitors}

\section{Hosted file}

table 2.pdf available at https://authorea.com/users/375120/articles/492481-surgery-withemicizumab-prophylaxis-for-two-pediatric-patients-with-severe-haemophilia-a-withinhibitors 